\title{
Oncogenic chromosomal translocations and human cancer (Review)
}

\author{
JIE ZHENG \\ Department of Pathology, School of Medicine, Southeast University, Nanjing, Jiangsu 210009, P.R. China
}

Received June 5, 2013; Accepted August 2, 2013

DOI: $10.3892 /$ or.2013.2677

\begin{abstract}
Chromosomal translocations are very common in human cancer. The molecular mechanisms of chromosomal translocations are complex and are not fully understood. Recent studies showed organization of genomes is higherorder in the nucleus and every chromosome or chromatin has its preferential position and territory. These findings suggest the spatial arrangements of chromosomes and gene loci in the interphase nucleus are responsible for non-random chromosomal translocations in human cancer. Chromosomal translocations are favored in neighboring chromosomes or genes in spatial proximity within the nucleus. Chromosomal translocations leading to cancer are generally via two ways, formation of oncogenic fusion protein or oncogene activation by a new promoter or enhancer. This review focuses mainly on the recent advances in oncogenic chromosomal translocations in human cancer.
\end{abstract}

\section{Contents}

1. Introduction

2. Chromosomal translocations are related to chromosome or gene positioning

3. Effects of oncogenic chromosomal translocations

4. Conclusion

\section{Introduction}

Chromosomal translocations are very common in human cancer, particularly in hematopoietic and lymphoid tumors (1). They are involved in the initiation of some types of cancer although the exact mechanism is not fully understood. These translocations may provide a selective growth advantage or

Correspondence to: Professor Jie Zheng, Department of Pathology, School of Medicine, Southeast University, 87 Ding Jia Qiao, Nanjing, Jiangsu 210009, P.R. China

E-mail: jiezheng54@126.com

Key words: cancer, chromosomal translocation, gene positioning, fusion protein, effect chance of subsequent mutations in some stem or progenitor cells, which may subsequently initiate the development of some malignant tumors. For oncogenic chromosomal translocations, gene rearrangements may change the original locations of proto-oncogenes to generate the obvious effects on phenotype via the two major ways $(2,3)$. One is to generate oncogenic fusion proteins. The best example is translocation between chromosomes 9 and 22 [t( 9;22)], i.e. Philadelphia (Ph) chromosome, in chronic myeloid leukemia (CML), resulting in the translocation of proto-oncogene $A B L$ at $9 \mathrm{q} 34$ to $B C R$ on chromosome 22. The formation of BCR-ABL oncoprotein has an abnormal activity of tyrosine kinase (TK) which is associated with the tumorigenesis of CML and acute lymphoblastic leukemia (ALL) (4). Another way is that proto-oncogenes are brought into proximity with the new cis-regulatory elements. The classic example is the overexpression of proto-oncogene $\mathrm{c}-M Y C$ in Burkitt lymphoma due to $\mathrm{t}(8 ; 14)$ to result c-MYC juxtaposed to immunoglobulin heavy chain (IGH) regulatory elements.

Chromosomal translocations in vivo are a complex biological process and there are two essential steps for the formation of chromosomal translocations. First, DNA double-strand breaks (DSBs) occur simultaneously at the two loci. Second, the ends of DSBs need to approach each other and are illegitimately joined together. Aside from these essential steps, increasing evidence shows that there are still several factors that influence the formation of chromosomal translocations, such as nuclear architecture, activation induced deaminase (AID)-mediated V(D)J recombination, gene expression, and other unknown mechanisms (5-7). In the present study, I focus on the effects of chromosome or gene positioning on chromosomal translocations, on the functional impacts owing to oncogenic chromosomal translocations in human cancer.

\section{Chromosomal translocations are related to chromosome or gene positioning}

Chromosomal translocations in cancer are generally considered to be no-random. The factors that could influence chromosomal translocation are complex and several factors, such as the spatial positions of broken loci, recombination, DNA repair elements, are involved. The two spatial proximal broken loci have more probability to illegitimately join than two distant broken loci (8). For example, investigations have shown that chromosomes 9 and 22 neighbor in lymphoid 
cells $(9,10)$. This may partly explain why $t(9 ; 22)$ easily occurs in lymphocytes. Similar to $t(9 ; 22), t(15 ; 17)$, resulting in the formation of promyelocytic leukemia-retinoic acid receptor $\alpha$ (PML-RAR $\alpha$ ) fusion oncoprotein, can be detected in most cells in acute promyelocytic leukemia (APL) (11). The study also showed that chromosomes 15 and 17 were close to each other in lymphoid cells (10); this may also partly explain why $\mathrm{t}(15 ; 17)$ easily occurs in hematopoietic cells. Furthermore, intergenic distance between the $P M L$ and $R A R \alpha$ or $B C R$ and $A B L$ is shorter in hematopoietic precursors than in B-lymphoid cells (10), consistent with the theory that cancer originates from stem cells.

The reason why $70 \%$ of Burkitt lymphomas, a B-cell tumor, often contains $\mathrm{t}(8 ; 14)$, i.e. the c-MYC gene (8q24) juxtaposes to $I G H$ gene (14q32) (Fig. 1B), is because chromosome 8 closes spatially chromosome 14 in B lymphocytes $(12,13)$. Research has shown that when B lymphocytes are stimulated, the $M Y C$ gene is preferentially recruited to the same transcription factory as the highly transcribed $I G H$ gene. While the c-MYC and $I G H$ are close to each other, it increases the incidence of specific chromosomal translocations (14). With the exception of $\mathrm{t}(8 ; 14), \mathrm{c}-M Y C$ less often rearranges with the immunoglobulin light chain $\kappa(I G K)$ or $\lambda(I G L)$ genes of chromosome 2 or 22 in Burkitt lymphoma, $\mathrm{t}(2 ; 8)(\mathrm{p} 11.2 ; \mathrm{q} 24.1)$ or $\mathrm{t}(8 ; 22)(\mathrm{q} 24.1 ; \mathrm{q} 11.2)$ places $\mathrm{c}-M Y C$ under the control of $I G K$ or $I G L$ locus, respectively, resulting in the overexpression of c-MYC. In fact, the mechanism of $\mathrm{t}(2 ; 8)$ or $\mathrm{t}(8 ; 22)$ translocation is similar to that of $t(8 ; 14)$ in Burkitt lymphoma, relating to spatial organization of the B cell genome (12).

Except for $\mathrm{t}(8 ; 14)$ in Burkitt lymphoma, a reciprocal translocation between chromosomes 14 and 18 is also extremely common in follicular lymphoma (70-95\%), a B cell lymphoma with follicular architecture. This translocation leads to the juxtaposition of the $B C L-2$ gene at $18 \mathrm{q} 21$ and the $I G H$ locus, resulting in anti-apoptotic protein BCL-2 overexpression (Fig. 1D). Measuring BCL-2 expression can be used to distinguish follicular lymphoma from benign follicular hyperplasia, in which BCL-2 expression is low (15). In mantle cell lymphoma, an aggressive subtype of B cell lymphoma, most tumor cells have a $\mathrm{t}(11 ; 14)$, i.e. the cyclin D1 $(C C N D 1)$ gene at $11 \mathrm{q} 13$ moves to $I H G$ locus, resulting in the overexpression of cyclin D1 (Fig. 1C) (16). Cyclin D1, a cell cycle regulator, is not expressed in normal B cells. In diffuse large B-cell lymphoma (DLBCL), approximately one third of patients have a $\mathrm{t}(3 ; 14)$, i.e. the oncogene $B C L-6$ on chromosome 3 moves to $I H G$ locus, resulting in the overexpression of $B C L-6$ (Fig. 1A), a specific transcriptional repressor that inhibits the differentiation of B cells. The mechanism of chromosomal translocations in follicular lymphoma, mantle cell lymphoma and DLBCL are similar to that in Burkitt lymphoma, relating to spatial proximity of translocation-prone gene loci in the interphase nucleus (12).

Approximately $60 \%$ of patients with anaplastic large-cell lymphoma (ALCL) have $t(2 ; 5)$, that leads to the formation of a characteristic fusion gene between anaplastic lymphoma kinase $(A L K)$ at $2 \mathrm{p} 23$ and nucleophosmin $(N P M)$ at $5 \mathrm{q} 35$. ALK, a receptor tyrosine kinase (RTK) belonging to the insulin receptor superfamily, has been reported to be active due to chromosomal translocations in several types of human cancer, such as ALCL, non-small cell lung carcinoma (NSCLC) and DLBCL $(17,18)$. ALK expression is generally restricted to neural tissue (19), $\mathrm{t}(2 ; 5)$ leading to the expression of truncated $A L K$ driven by $N P M$ promoter in lymphocytes. Accumulating evidence suggests that DSBs and the formation of translocation are preceded by the two gene loci being in close proximity. For example, Mathas et al (20) found that the formation of $A L K-N P M$ fusion gene was related to spatial proximity of two gene loci which was prior to the generation of translocation. This spatial proximity of two gene loci leads to upregulation of ALK which facilitates to induce DSBs.

Aside from interchromosomal translocations, intrachromosomal translocations are also associated with spatial distance of two gene loci. For example, $60-70 \%$ of papillary thyroid carcinomas have a characteristic inv(10)(q11.2q21), i.e. breakpoint $R E T$ (10q11.2) is relegated to opposite breakpoint the H4 (D10S170) or NCOA4 (ELE1) gene (10q21) in the same chromosome (21). RET, an RTK, is often found in translocation in papillary thyroid carcinoma (PTC), particularly in patients who had radiation exposure. The $\mathrm{H} 4$ protein is widely expressed in the nucleus and cytoplasm and its function is unknown (22). According to the different rearrangement loci, to date, PTC has 11 rearranged forms, referred to as PTC1-11 (23). PTC1(H4, CCDC6)-RET and PTC3(NCOA4)-RET are the most common intrachromosomal rearrangements in PTC. By contrast, PTC2-RET and other less common types of PTC-RET are interchromosomal translocations (24). These rearrangements can lead to constitutively ligand-independent RET activity, involved in thyroid carcinogenesis. Although the distances between RET and $H 4$ loci are $18 \mathrm{Mb}$, chromosome folding can offer two loci close to each other in thyroid cells, thus increasing the probability of recombination between them in the interphase nuclei. This chromosomal folding is specific for thyroid cells, and this may explain why inv(10)(q11.2q21) is frequently seen in PTC (25). The translocation of $H 4$ and RET occurs less in other types of cells. If it happens in non-thyroid cells, this type of translocation may not cause tumor.

Hormones also influence chromosomal translocations via their receptors. Previous studies showed that $\sim 50 \%$ of prostate cancer cases have del(21)(q22) and t(7;21) (1,26-28), resulting in the translocation of an ETS (E26 transformation-specific)regulated gene (ERG) (21q22.3) or ETS variant 1 (ETVI) gene (7p21.2) to the transmembrane protease serine 2 (TMPRSS2) gene (21q22.2) promoter region, which contains androgen receptor (AR) binding sites (29). ETS is a transcription factor family in which every family member contains ETS domain, a winged helix-loop-helix DNA binding domain. To date, 28 members of ETS have been identified, such as FLI (11q24), ERG, ETV1, ETV4 (17q21), ETV5 (3q) and ETV6 (12p13) (30). The translocations of ETS are often found in human cancer, such as Ewing sarcoma $(31,32)$, leukemia $(33,34)$, prostate cancer (1,27-28) and breast cancer (35). TMPRSS2 is a specific expression gene in the prostate and its expression is increased in prostate cancer $(28,36)$. Although it is $2.7 \mathrm{Mb}$ genomic distances between $E R G$ and TMPRSS2 on the same chromosome and TMPRSS2 and ETV1 are on the different chromosomes, $E R G$ and $E T V 1$ regulatory regions also have AR binding sites and androgen can induce TMPRSS 2 and $E R G$ or ETV1 spatial proximity via AR $(27,28,37,38)$. These studies explain why the TMPRSS2-ERG and TMPRSS2-ETVI translocations are easily seen in prostate cancer as the prostate is an androgen-sensitive organ. That hormones induce inter- 


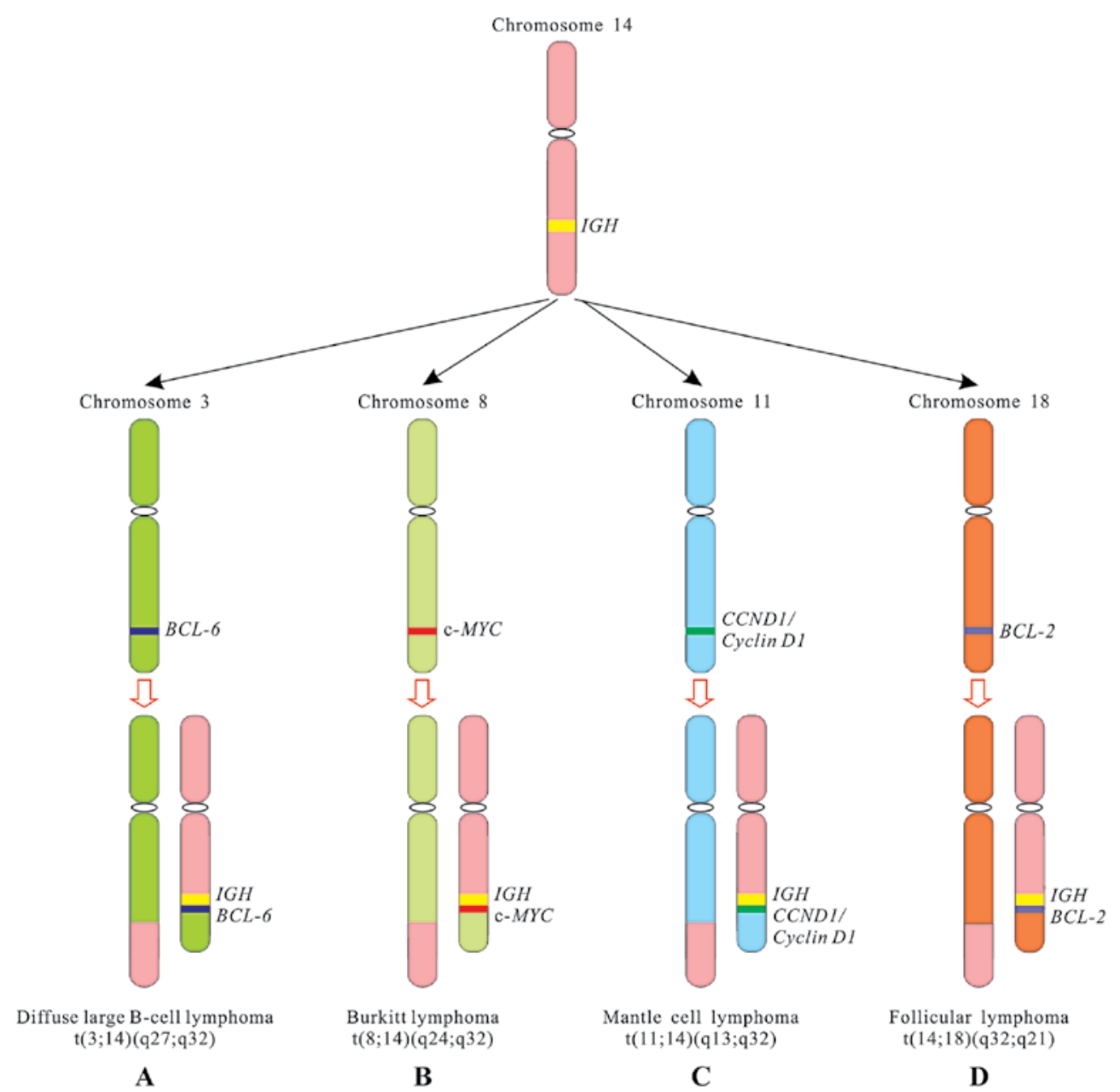

Figure 1. Proto-oncogenes are under the control of the cis-IGH-regulatory elements in B cell malignancies. IGH is on chromosome 14. Chromosomal translocations make c-MYC and other proto-oncogenes under the control of cis-IGH locus in Burkitt lymphoma and other B cell lymphomas (as indicated).

actions between gene loci on different chromosomes is also found in estrogen. Hu et al (39) reported that estrogen induced rapid chromosome interactions to coordinate specific gene expression via estrogen receptor $\alpha(\mathrm{ER} \alpha)$.

In general, when DSBs occur, the ends of DSBs are relatively stable and mobile $<250 \mathrm{~nm}$ (40), supporting the observation that chromosomal translocations occur in close genes. We can image if the broken ends are relatively stable, they may be rejoined by themselves, thereby preventing chromosomal translocation. If the broken ends roam, it increases the chances of illegitimate recombination. Thus, the relative stability of the broken ends decreases the probability of gene rearrangement and favor genomic integrity $(40,41)$.

\section{Effects of oncogenic chromosomal translocations}

Effects of oncogenic chromosomal translocations on cellular phenotypes are complex and diverse. Following translocations, oncogenes may influence cellular phenotypes via the formation of oncogenic fusion proteins or under the control of the new regulatory elements (1-3).

Oncogenic fusion proteins. Although the products of oncogenic fusion genes are diverse, they can primarily be classified into two groups, transcription factors and TKs. Several onco- genic fusion proteins are transcription factors and TKs. In fact, the products of fusion genes are diverse; some may be neutral, some may play less important roles in cellular phenotypes and some may cause cell death in which we can not see this type of the translocation. The translocations found in cancer, however, clearly have critical functions in tumorigenesis. Generally, transcription factors and TKs play more important roles in cellular phenotypes, and this may partly explain why many fusion proteins detected in human cancer are transcription factors and TKs. It should be noted, that these so-called oncogenic fusion proteins as transcription factors and TKs are already different from their functions of parental proteins in several aspects and they often acquire some new functions.

It is clear that the sites of DSBs are related to the functional consequences of fusion genes. DSBs are not random (42) and occur preferentially in large and evolutionarily conserved genes $(43,44)$, fragile sites $(45)$, transcription start sites $(14,46,47)$ and euchromatin $(48,49)$. The breakpoints do not usually occur in their functional domains if these genes are encoded for transcription factors or TKs, thus fusion proteins can still retain the activities of transcription factors or TKs (42). Several studies have shown that DSBs preferentially occur in euchromatin, consistent with a greater chance for translocation to occur in the sites with transcription activity $(14,46,47)$. Following exposure to ionizing radiation, DSBs occur more 
often in euchromatin than heterochromatin, suggesting the highly compacted chromatin can prevent from radiation damage. From another point, euchromatin is relatively loose and has a lack of protective mechanism, so it is easily attacked by radiation $(48,49)$. In addition, the mechanisms of DSB repair in euchromatin are also different from heterochromatin. Since the time for DSB repair in heterochromatin is longer than euchromatin $(50,51)$, by extrapolation, the higher frequency of chromosomal translocations in euchromatin than in heterochromatin is reasonable.

Oncogenic fusion protein as transcription factor. The products of several oncogenic fusion genes function as transcription factors. In this group, each fusion protein consists of $\mathrm{N}$-terminal partner fused to the DNA binding domain at the C-terminus (Fig. 2). For example, EWS-FLI fusion protein, a characterized protein in Ewing sarcoma, consists of $\mathrm{N}$-terminal part of EWS, a member of the TET family at the N-terminus, and C-terminal part of FLI, a member of the ETS family, at the C-terminus (31). As a chimeric transcription factor, EWS-FLI fusion protein has different transcription functions compared to its parental transcription factor FLI (32), despite identical DNA-binding domain. This mistargeting is associated with 85\% of Ewing sarcoma development (52).

The functions of the fusion proteins as oncogenic transcription factors are various. Some stimulate gene expression, such as TMPRSS2-ERG and TMPRSS2-ETV1. Whether the TMPRSS2-ETS are really fusion proteins is under debate. Some people consider that the TMPRSS2-ETS translocations are the expression of ETS under the influence of the TMPRSS2 promoter as the expression of MYC under the $I G H$ regulatory elements in Burkitt lymphoma (2). In fact, the TMPRSS2-ETS translocations are very heterogeneous, both TMPRSS2 at the 5'-end and ETS at the 3'-end have different fusion forms which generate different fusion transcripts, including splice variants $(26,29,53,54)$. In most cases, the TMPRSS2 promoter and first exon or first 2 exons are juxtaposed to the ETS exons, with deletion of the ETS promoter and first exon or first 2 exons (55). Therefore, the fusion genes are under the control of the androgen-regulated TMPRSS2 promoter, resulting in the high level expression of oncogenic ETS fusion genes. For example, TMPRSS2-ERG gene fusion is the most common among these translocations and some are composed of the TMPRSS 2 promoter and the first exon at the 5 '-end and the transcription factor domain of $E R G$ at the 3'-end, resulting in a truncated ERG protein lacking TMPRSS 2 as the TMPRSS2 exon 1 is noncoding and does not contain an ATG (53), some are composed of the TMPRSS 2 promoter and the first 2 exons (exon 2 containing an $A T G$ at 142$)$ at the 5 '-end and the transcription factor domain of $E R G$ at the 3'-end (designed type VI), resulting in a true fusion protein containing the first 5 amino acids of the TMPRSS2 at the N-terminus and a slightly truncated ERG protein at the C-terminus (Fig. 2) (53). Androgen can stimulate the transcription of the TMPRSS2-ETS fusion since all TMPRSS2-ETS fusions retain the TMPRSS2 promoter which contains AR binding sites. In most cases, ETS retains DNA-binding domain, which can stimulate the transcription of target genes for cell growth, invasion and metastasis and promote prostate cancer progression $(26,28)$.

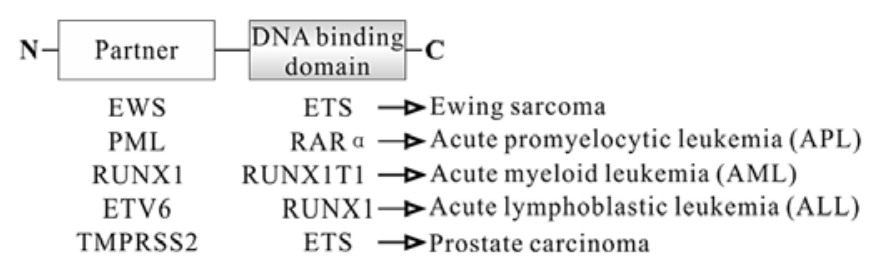

Figure 2. The functions of fusion proteins as transcription factors and associated malignant tumors. Fusion proteins consist of two parts (from different genes). The functions of these fusion proteins are different from their parental proteins. The N-terminal partners provide transactivation domains or dimerization/oligomerization domains. In the C-terminus, these oncogenic fusion proteins retain the DNA binding domains.

Some inhibit gene expression, such as $\mathrm{t}(12 ; 21) / \mathrm{ETV} 6-$ (TEL1)-RUNX1(runt-related transcription factor 1, previously known as AML1), $t(8 ; 21) / R U N X 1-R U N X I T 1(E T O), t(15 ; 17) /$ PML-RAR $\alpha$ and inv(16)/CBFB-MYH11, which inhibit the transcriptional activity of genes required for normal differentiation of hematopoietic cells. Although these fusion proteins may not be sufficient to induce leukemia alone (56), they increase the developmental risk of acute leukemia in patients with these fusion proteins $(4,34,57)$. These fusion proteins repress the functions of transcription via the different molecular mechanisms. For example, RUNX1-RUNXIT1 protein is found in $\sim 13 \%$ of acute myeloid leukemia (AML) (58). In RUNX1-RUNXIT1 protein, the translocation deletes the transactivation domain but retains the runt homology domain (RHD) responsible for binding to DNA at N-terminus of RUNX1 (Fig. 2) (59). RUNX1-RUNXIT1 protein interferes with wild-type RUNX1-dependent transcription via RUNXIT1 recruiting the nuclear corepressor (N-CoR)-histone deacetylase (HDAC) complex (60). ETV6-RUNX1 protein is the most common abnormality in childhood ALL, occurring in 25\% (4). In ETV6-RUNX1 protein, the translocation deletes the ETS domain of ETV6, a member of the ETS family, but retains the runt domain of RUNX1 (Fig. 2). Similar to the RUNX1-RUNXIT1 protein as a dominant negative inhibitor of RUNX1, the ETV6RUNX1 protein represses RUNX1-dependent transcription via ETV6 recruiting N-CoR-HDAC complex (61). RUNX1 targeting genes are required for normal hematopoietic cell development. PML-RAR $\alpha$ protein is linked to the development of APL, a genetic distinct subtype of AML. This fusion protein is composed of most of the functional domains of RAR $\alpha$ (including the RAR binding domain and the DNA binding domain) and the majority of PML, including dimerization domain (Fig. 2). As a transcription factor, wild-type RAR $\alpha$ releases SMRT/N-CoR corepressor after binding retinoic acid (RA) and induces the transcription of target genes that promote cell differentiation. However, this fusion protein alters the sensitivity to physiological levels of RA and impairs the release of SMRT/N-CoR corepressor from RAR $\alpha$, therefore blocking the differentiation of promyelocytes (62). One of the mechanisms of pharmacologic levels of all-trans retinoic acid (ATRA) treatment APL promotes the release of the corepressor from RAR $\alpha$ and recovers RA response (11). Arsenic trioxide $\left(\mathrm{As}_{2} \mathrm{O}_{3}\right)$ is also used to treat APL by promoting degradation of PML-RAR $\alpha$ protein (63). 
There are some mistarget gene expressions, such as mixed lineage leukemia (MLL) fusions (64). MLL gene on 11q23 is often rearranged with other partner genes in ALL and AML, accounting for $8 \%$ of pediatric and $10 \%$ of adult ALL (4), $15-20 \%$ of pediatric AML and $<3 \%$ of adult AML (65), or biphenotypic (mixed lineage) leukemias. The $M L L$ gene encodes a complex DNA binding protein with histone $\mathrm{H} 3$ lysine 4 (H3K4)-specific methyltransferase activity, which positively regulates gene expression including HOX genes. MLL protein consists of multiple functional domains, including the AT-hooks, DNA methyltransferase homology domain that contains a CXXC zinc finger motif and trithorax PHD domains at the N-terminus, the transactivation domain (TAD) and SET domain that possesses H3K4 methyltransferase activity at the C-terminus. Post-translationally, taspase I cleaves MLL to generate two fragments (MLLN p300 and MLLC p180) that form a stable complex by direct interaction of the FYRN and FYRC domains (66). Unlike classical sequence-specific DNA-binding transcription factor, MLL regulates the expression of target genes via epigenetic mechanisms, such as DNA and histone methylation modification (66).

Chromosomal translocations lead to the fusion of 5'-end portion of MLL to one of $>60$ different partner genes, resulting in the formation of different fusion genes, such as $M L L-A F 4$ (4q21), MLL-AF9 (9p22), MLL-ENL (19p13.3), MLL-AF10 (10p12), MLL-AF6 (6q27), MLL-ELL (19p13.1) (Fig. 3) (66,67). All MLL fusion proteins retain N-terminal AT-hooks, DNA methyltransferase homology domain, thus preserving DNA binding activity whereas the trithorax PHD domains, TAD and SET domains are always replaced by the partners. In these fusions, the original MLL H3K4 methyltransferase activity is replaced by the partners which play a critical role in MLL oncoproteins (68). Although MLL fusion proteins lose the activity of $\mathrm{H} 3 \mathrm{~K} 4$ methylation, these fusion proteins gain the activity of H3K79 methylation via recruiting the H3K79 methyltransferase hDOT1L which can cause dysregulation of whole genomic expression and is associated with MLL leukemogenesis $(67,69)$. Since hDOT1L plays a key role in the development of MLL leukemia, hDOT1L is an ideal target for MLL leukemia. Several hDOT1L inhibitors are underdeveloped. In particular, EPZ004777, a specific hDOT1L inhibitor, seems to be a promising drug for leukemia with MLL gene translocation (70).

Since $>60$ MLL fusion proteins have been found (71), the functions of MLL fusion proteins are very different, and the functions of some MLL fusion proteins remain unclear or not fully understood. To date, we know that MLL oncoproteins induce leukemia through several pathways. First, MLL oncoproteins act as transcriptional regulators that can bind DNA and induce aberrant expression of leukemic stem cell target genes, such as HOX, MEISI, WNT and RNA polymerase II. Among MLL target genes, transcription factor $H O X$ genes are particular and essential for MLL leukemogenesis (72). MLL-ENL, MLL-ELL, MLL-AF4, MLL-AF9 and MLL-AF10 have been demonstrated to induce acute leukemia using this pathway (Fig. 3) (67,73-75). Second, MLL fusion partners provide a dimerization motif, such as AF1p/Eps15 and GAS7. The MLL dimerization/oligomerization proteins can recruit co-activators or basal transcriptional machinery to result in the aberrant expression of target genes for inducing

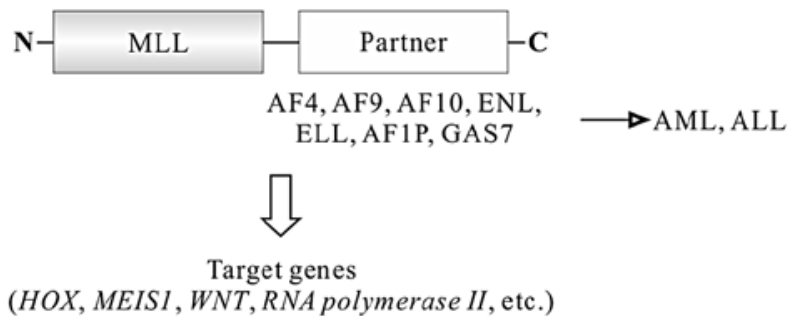

Figure 3. MLL fusions. At least $>60$ MLL chimeric proteins have been found in which the N-terminal portion of MLL is fused to the C-terminal portion of the partner. Unlike classical sequence-specific DNA-binding transcription factor, MLL fusions mainly regulate the expression of target genes via epigenetic mechanisms.

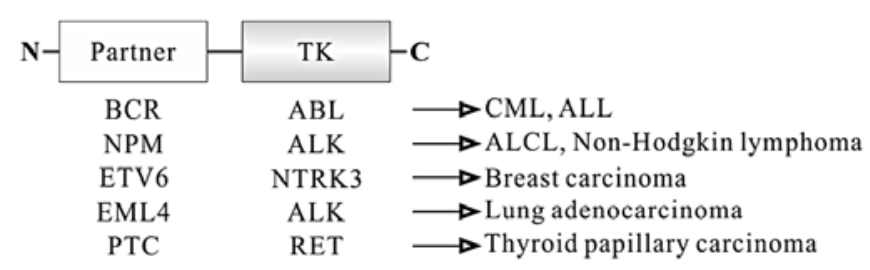

Figure 4. The functions of fusion proteins as TKs and associated malignant tumors. The functions of these fusion proteins are different from their parental proteins.

acute leukemia (76,77). Third, MLL fusion partners increase the stabilization of MLL oncoproteins. For example, all MLL-AF4, MLL-AF9, MLL-ENL and MLL-ELL exhibit resistance to degradation mediated by the cell cycle ubiquitin-proteasome system (71).

Oncogenic fusion protein as tyrosine kinase. Another group of oncogenic fusion proteins harbor activities of TKs. In this group, each translocation generates a different fusion protein consisting of $\mathrm{N}$-terminal partner fused to the TK domain at the C-terminus (Fig. 4). TK domain in these fusion proteins is intact although they are the truncated proteins $(2,78,79)$. For example, in ALCL, ALK breakpoints are located in the intron flanked by exons 16 and 17, and exons 17-26 encoding the intracytoplasmic kinase domain of ALK are intact (80). It is similar to that of RET in PTC (81). As the regulatory parts of kinase are often lost and replaced by unrelated sequences, the kinase activity of these fusion proteins is determined by the $\mathrm{N}$-terminal partners. In most cases, the N-terminal partners supply domains that promote dimerization/oligomerization, allowing fusion kinase to be activated in the absence of physiological stimulating signals (79,81-85).

BCR-ABL fusion protein is linked to the development of CML and ALL (4). ABL protein has two isoforms, 1a and b. ABL1b contains a C14 myristoyl saturated fatty acid moiety covalently linked to the Cap region at the N-terminus and is expressed at higher levels than ABL1a, which is not myristoylated. The Cap region of ABL contains endogenous autoregulatory domain which can inhibit kinase activity via stabilizing SH3 and SH2 domains of ABL $(86,87)$. This fusion protein is composed of the majority of BCR at the $\mathrm{N}$-terminus and most of the functional domains of $\mathrm{ABL}$ 
except Cap domain at the C-terminus (Fig. 4), resulting in the disregulatory activation of BCR-ABL TK (88). In addition, oligomerization domain and GRB2-binding site at tyrosine 177 (Y177) in BCR partner are also essential for BCR-ABL-mediated CML $(82,89)$. Imatinib/Gleevec ${ }^{\circledR}$, a specific BCR-ABL inhibitor, was the first molecular target drug approved by the US Food and Drug Administration (FDA) to treat patients with CML in 1996. Dasatinib and nilotinib, second generation inhibitors of $\mathrm{ABL}$, have also been approved to treat patients with imatinib-resistant CML (90).

H4-RET fusion protein is the most common chromosomal translocation in PTC, and accounts for $60-70 \%$ of PTC. This protein consists of the $\mathrm{N}$-terminal promoter and leucine zipper domain of $\mathrm{H} 4$ at the $\mathrm{N}$-terminus and the TK domains of RET at the C-terminus (Fig. 4). RET lacks the signal peptide and transmembrane domain in this chimeric oncoprotein, thus the aberrant TK activity of RET fusion is controlled by $\mathrm{H} 4$ partner which provides an active promoter and dimerization domain for ligand-independent activation of the fusion protein (91).

Approximately 5\% of NSCLCs have inv(2)(p21;p23), resulting in the formation of echinoderm microtubule-associated protein-like 4(EML4)-ALK fusion gene (85). EML4-ALK protein consists of various length EML4 containing the coiled-coil domain at the N-terminus and the intracellular catalytic domain of ALK at the C-terminus (Fig. 4). As ALK lacks the extracellular and transmembrane domain in this oncoprotein, so EML4 partner constitutively activates the TK of ALK via the dimerization of EML4-ALK, involved in the carcinogenesis of NSCLC (85). EML4-ALK is most commonly detected in non-smokers with NSCLC. NSCLC with EML4-ALK has unique pathological and clinical features, such as Asian patients, younger, adenocarcinoma and lack of EGFR and KRAS mutations (92). Crizotinib, an ALK inhibitor, was recently approved by the FDA to treat patients with ALK-positive NSCLC (93).

Oncogenes under the control of a stronger promoter. Proto-oncogenes are brought into proximity with the new cis-regulatory elements, leading to their overexpression which is seen in several types of lymphoma and leukemia, particularly in B and T cell malignancies. This is because V(D)J recombination exists during $\mathrm{B}$ and $\mathrm{T}$ cell development, which generates antibody and T cell receptor (TCR) diversity. However, $\mathrm{V}(\mathrm{D}) \mathrm{J}$ recombination may also increase the risk of chromosomal translocation in the same regions, which may partly explain why chromosomal translocation frequently occurs in several types of lymphoma and leukemia. For example, the overexpression of oncogenes $c-M Y C, B C L-2, C C N D 1$ and $B C L-6$ in $B$ cell lymphomas may be associated with errors in $\mathrm{V}(\mathrm{D}) \mathrm{J}$ recombination (Fig. 1) (16,94-96), suggesting the mechanism of chromosomal translocations in these B cell lymphomas is similar.

In a subset of T cell ALL (T-ALL), chromosomal translocation can make proto-oncogenes under the control of TCR regulatory elements, resulting in the deregulated transcription of these proto-oncogenes, such as TLX1 (HOX11), TLX3 (HOX11L2), LMO1, LMO2, c-MYC, LYL1, T-cell acute lymphocytic leukemia-1/stem cell leukemia (TAL1/SCL), TAL2 and NOTCH1 (Fig. 5). TLX1 and TLX3 belong to

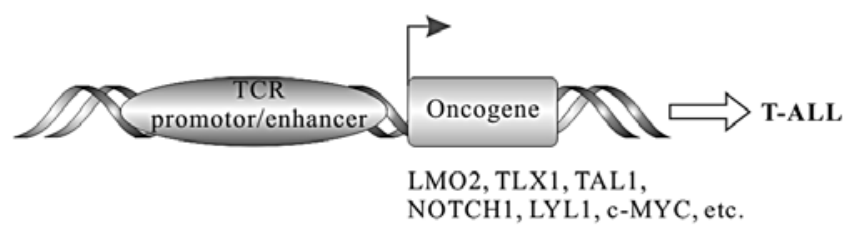

Figure 5. Oncogenes are under the control of the $T C R$ promoter/enhancer in a subset of T-ALL. The promoter is usually located upstream of the gene, while the enhancer can be located upstream, downstream, or even within the gene it control. In T-ALL, the chromosomal translocations are mainly involved in the $T C R$ enhancer.

homeobox transcription factors. LIM domain only (LMO) 1 and LMO2 belong to LIM transcription factors containing LIM zinc-finger motifs. c-MYC, LYL1, TAL1/SCL and TAL2 belong to basic helix-loop-helix (bHLH) transcription factors. NOTCH1, one of NOTCH family, is a transmembrane protein.

The TCR is composed of two different protein chains. In $95 \%$ of $\mathrm{T}$ cells, TCR consists of $\alpha \beta$ chains, whereas in $5 \%$ of $\mathrm{T}$ cells, TCR consists of $\gamma \delta$ chains. TCR $\alpha$ (TCRA) and $\delta(T C R D)$ chain genes are localized on 14q11.2, TCR $\beta$ $(T C R B)$ and TCR $\gamma(T C R G)$ loci are localized on $7 \mathrm{q} 34$ and $7 \mathrm{p} 15$, respectively. The breakpoints often occur in $T C R A / D$ or $T C R B$. The $\mathrm{t}(11 ; 14)(\mathrm{p} 13 ; \mathrm{q} 11)$ and $\mathrm{t}(7 ; 11)(\mathrm{q} 34 ; \mathrm{p} 13)$ have been found in $3 \%$ T-ALL (97). Both translocations lead to $L M O 2$ (11p13) under the control of the TCRD or TCRB locus, resulting in LMO2 overexpression which may be involved in the T-ALL development (98). Proto-oncogene TLX1 (T-cell leukemia homeobox 1, previously known as HOX11 or TCL3) on 10q24 is normally not expressed in $\mathrm{T}$ cells and its expression is often deregulated in T-ALL (99). This deregulated expression of $T L X 1$ is related to $\mathrm{t}(7 ; 10)$ (q34;q24) and $\mathrm{t}(10 ; 14)(\mathrm{q} 24 ; \mathrm{q} 11)$ which account for $7 \%$ of childhood and $31 \%$ of adult T-ALL (97). These translocations make $T L X 1$ under the control of the TCRB or TCRA locus, resulting in the overexpression of $T L X 1$ which may contribute to T-ALL via blocking apoptosis of developing $\mathrm{T}$ cell in the thymus (100). TLX1 overexpression has also been demonstrated in the absence of a 10q24 rearrangement, suggesting that other mechanisms, such as epigenetic alterations, can lead to this aberrant expression of $T L X 1(101,102)$. The situation is similar to TAL1 (1p32). Approximately $7 \%$ of childhood T-ALL and $12 \%$ of adult T-ALL have $t(1 ; 14)$ (p32;q11), leading to deregulated expression of TAL1 under control of the TCRA/D loci (4). However, the overexpression of TAL1 in T-ALL also occurs in the absence of TAL1 rearrangement, suggesting that other mechanisms may influence the overexpression of TAL1 (103).

NOTCH1 plays crucial roles in cell development, hematopoietic stem cell maintenance and $\mathrm{T}$ cell fate specification in the mature organism (104). NOTCH1 is regarded as an oncoprotein. In a low number of human T-ALL patients, they had $\mathrm{t}(7 ; 9)(\mathrm{q} 34 ; \mathrm{q} 34.3)$ which results to fuse the 3 ' end of NOTCH1 (9q34.3) to TCRB locus, leading to overexpression of a truncated NOTCH1 protein that lack the negative regulatory region (NRR) (105). NRR is NOTCH1 extracellular domain and responsible for preventing ligand-independent receptor activation. 


\section{Conclusion}

Chromosomal translocations in human cancer are not random and tend to occur in some specific sites with spatial proximity in genome organization. The oncogenic chromosomal translocations may provide a selective growth advantage or chance of secondary mutations in some stem or progenitor cells via different pathways, such as the formation of oncogenic fusion proteins and under the control of the new regulatory elements. Understanding the mechanisms of chromosomal translocations in cancer may help us to develop new approaches in early the diagnosis and target therapy of cancer.

\section{Acknowledgements}

Dr Peng Gao is acknowledged for the images and comments on this review. This study was in part supported by a grant from the Ministry of Education, China (no. 20110092110043).

\section{References}

1. Mitelman F, Johansson B and Mertens F: The impact of translocations and gene fusions on cancer causation. Nat Rev Cancer 7 : 233-245, 2007.

2. Nambiar M, Kari V and Raghavan SC: Chromosomal translocations in cancer. Biochim Biophys Acta 1786: 139-152, 2008.

3. Fröhling S and Döhner H: Chromosomal abnormalities in cancer. N Engl J Med 359: 722-734, 2008.

4. Pui CH, Relling MV and Downing JR: Acute lymphoblastic leukemia. N Engl J Med 350: 1535-1548, 2004.

5. Aplan PD: Causes of oncogenic chromosomal translocation. Trends Genet 22: 46-55, 2006.

6. Raghavan SC and Lieber MR: DNA structures at chromosomal translocation sites. Bioessays 28: 480-494, 2006.

7. Hakim O, Resch W, Yamane A, et al: DNA damage defines sites of recurrent chromosomal translocations in B lymphocytes. Nature 484: 69-74, 2012.

8. Meaburn KJ, Misteli T and Soutoglou E: Spatial genome organization in the formation of chromosomal translocations. Semin Cancer Biol 17: 80-90, 2007.

9. Kozubek S, Lukásová E, Marecková A, et al: The topological organization of chromosomes 9 and 22 in cell nuclei has a determinative role in the induction of $\mathrm{t}(9,22)$ translocations and in the pathogenesis of $\mathrm{t}(9,22)$ leukemias. Chromosoma 108: 426-435, 1999.

10. Neves H, Ramos C, da Silva MG, Parreira A and Parreira L: The nuclear topography of ABL, BCR, PML, and RAR $\alpha$ genes: evidence for gene proximity in specific phases of the cell cycle and stages of hematopoietic differentiation. Blood 93: 1197-1207, 1999.

11. Collins SJ: Retinoic acid receptors, hematopoiesis and leukemogenesis. Curr Opin Hematol 15: 346-351, 2008.

12. Roix JJ, McQueen PG, Munson PJ, Parada LA and Misteli T: Spatial proximity of translocation-prone gene loci in human lymphomas. Nat Genet 34: 287-291, 2003.

13. Misteli T: The inner life of the genome. Sci Am 304: 66-73, 2011

14. Osborne CS, Chakalova L, Mitchell JA, et al: Myc dynamically and preferentially relocates to a transcription factory occupied by Igh. PLoS Biol 5: e192, 2007.

15. Cornfield DB, Mitchell DM, Almasri NM, Anderson JB, Ahrens KP, Dooley EO and Braylan RC: Follicular lymphoma can be distinguished from benign follicular hyperplasia by flow cytometry using simultaneous staining of cytoplasmic bcl-2 and cell surface CD20. Am J Clin Pathol 114: 258-263, 2000.

16. Welzel N, Le T, Marculescu R, et al: Templated nucleotide addition and immunoglobulin $J_{H}$-gene utilization in $\mathrm{t}(11 ; 14)$ junctions: implications for the mechanism of translocation and the origin of mantle cell lymphoma. Cancer Res 61: 1629-1636, 2001.

17. Palmer RH, Vernersson E, Grabbe $\mathrm{C}$ and Hallberg B: Anaplastic lymphoma kinase: signalling in development and disease. Biochem J 420: 345-361, 2009.

18. Barreca A, Lasorsa E, Riera L, et al: Anaplastic lymphoma kinase in human cancer. J Mol Endocrinol 47: R11-R23, 2011.
19. Iwahara T, Fujimoto J, Wen D, et al: Molecular characterization of ALK, a receptor tyrosine kinase expressed specifically in the nervous system. Oncogene 14: 439-449, 1997.

20. Mathas S, Kreher S, Meaburn KJ, et al: Gene deregulation and spatial genome reorganization near breakpoints prior to formation of translocations in anaplastic large cell lymphoma. Proc Natl Acad Sci USA 106: 5831-5836, 2009.

21. Gandhi M, Evdokimova V and Nikiforov YE: Mechanisms of chromosomal rearrangements in solid tumors: the model of papillary thyroid carcinoma. Mol Cell Endocrinol 321: 36-43, 2010.

22. Merolla F, Pentimalli F, Pacelli R, Vecchio G, Fusco A, Grieco $\mathrm{M}$ and Celetti A: Involvement of H4(D10S170) protein in ATM-dependent response to DNA damage. Oncogene 26: 6167-6175, 2007.

23. Nikiforov YE: Thyroid carcinoma: molecular pathways and therapeutic targets. Mod Pathol 21 (Suppl 2): S37-S43, 2008.

24. Ciampi R, Giordano TJ, Wikenheiser-Brokamp K, Koenig RJ and Nikiforov YE: HOOK3-RET: a novel type of RET/PTC rearrangement in papillary thyroid carcinoma. Endocr Relat Cancer 14: 445-452, 2007.

25. Gandhi M, Medvedovic M, Stringer JR and Nikiforov YE: Interphase chromosome folding determines spatial proximity of genes participating in carcinogenic RET/PTC rearrangements. Oncogene 25: 2360-2366, 2006.

26. Clark J, Merson S, Jhavar S, et al: Diversity of TMPRSS2-ERG fusion transcripts in the human prostate. Oncogene 26: 2667-2673, 2007.

27. Lin C, Yang L, Tanasa B, et al: Nuclear receptor-induced chromosomal proximity and DNA breaks underlie specific translocations in cancer. Cell 139: 1069-1083, 2009.

28. Squire JA, Park PC, Yoshimoto M, Alami J, Williams JL, Evans A and Joshua AM: Prostate cancer as a model system for genetic diversity in tumors. Adv Cancer Res 112: 183-216, 2011.

29. Kumar-Sinha C, Tomlins SA and Chinnaiyan AM: Recurrent gene fusions in prostate cancer. Nat Rev Cancer 8: 497-511, 2008.

30. Seth A and Watson DK: ETS transcription factors and their emerging roles in human cancer. Eur J Cancer 41: 2462-2478, 2005.

31. Sankar S and Lessnick SL: Promiscuous partnerships in Ewing's sarcoma. Cancer Genet 204: 351-365, 2011.

32. Patel M, Simon JM, Iglesia MD, Wu SB, McFadden AW, Lieb JD and Davis IJ: Tumor-specific retargeting of an oncogenic transcription factor chimera results in dysregulation of chromatin and transcription. Genome Res 22: 259-270, 2012.

33. Zelent A, Greaves M and Enver T: Role of the TEL-AML1 fusion gene in the molecular pathogenesis of childhood acute lymphoblastic leukaemia. Oncogene 23: 4275-4283, 2004.

34. Bohlander SK: ETV6: a versatile player in leukemogenesis. Semin Cancer Biol 15: 162-174, 2005.

35. Li Z, Tognon CE, Godinho FJ, et al: ETV6-NTRK3 fusion oncogene initiates breast cancer from committed mammary progenitors via activation of AP1 complex. Cancer Cell 12: 542-558, 2007.

36. Vaarala MH, Porvari K, Kyllönen A, Lukkarinen O and Vihko P: The TMPRSS2 gene encoding transmembrane serine protease is overexpressed in a majority of prostate cancer patients: detection of mutated TMPRSS 2 form in a case of aggressive disease. Int $\mathrm{J}$ Cancer 94: 705-710, 2001.

37. Mani RS, Tomlins SA, Callahan K, et al: Induced chromosomal proximity and gene fusions in prostate cancer. Science 326: 1230 , 2009.

38. Bastus NC, Boyd LK, Mao X, et al: Androgen-induced TMPRSS2:ERG fusion in nonmalignant prostate epithelial cells. Cancer Res 70: 9544-9548, 2010

39. Hu Q, Kwon YS, Nunez E, et al: Enhancing nuclear receptorinduced transcription requires nuclear motor and LSD1-dependent gene networking in interchromatin granules. Proc Natl Acad Sci USA 105: 19199-19204, 2008.

40. Soutoglou E, Dorn JF, Sengupta K, et al: Positional stability of single double-strand breaks in mammalian cells. Nat Cell Biol 9: 675-682, 2007.

41. Parada LA, McQueen PG and Misteli T: Tissue-specific spatial organization of genomes. Genome Biol 5: R44, 2004.

42. Ortiz de Mendíbil I, Vizmanos JL and Novo FJ: Signatures of selection in fusion transcripts resulting from chromosomal translocations in human cancer. PLoS One 4: e4805, 2009.

43. Bickmore WA and Teague P: Influences of chromosome size, gene density and nuclear position on the frequency of constitutional translocations in the human population. Chromosome Res 10: 707-715, 2002. 
44. Narsing S, Jelsovsky Z, Mbah A and Blanck G: Genes that contribute to cancer fusion genes are large and evolutionarily conserved. Cancer Genet Cytogenet 191: 78-84, 2009.

45. Burrow AA, Williams LE, Pierce LC and Wang YH: Over half of breakpoints in gene pairs involved in cancer-specific recurrent translocations are mapped to human chromosomal fragile sites. BMC Genomics 10: 59, 2009.

46. Branco MR and Pombo A: Intermingling of chromosome territories in interphase suggests role in translocations and transcription-dependent associations. PLoS Biol 4: e138, 2006.

47. Chiarle R, Zhang Y, Frock RL, et al: Genome-wide translocation sequencing reveals mechanisms of chromosome breaks and rearrangements in B cells. Cell 147: 107-119, 2011.

48. Obe G, Pfeiffer P, Savage JR, et al: Chromosomal aberrations: formation, identification and distribution. Mutat Res 504: 17-36, 2002.

49. Cowell IG, Sunter NJ, Singh PB, Austin CA, Durkacz BW and Tilby MJ: $\gamma \mathrm{H} 2 \mathrm{AX}$ foci form preferentially in euchromatin after ionising-radiation. PLoS One 2: e1057, 2007.

50. Lorat Y, Schanz S, Schuler N, Wennemuth G, Rübe C and Rübe CE: Beyond repair foci: DNA double-strand break repair in euchromatic and heterochromatic compartments analyzed by transmission electron microscopy. PLoS One 7: e38165, 2012.

51. Murray JM, Stiff T and Jeggo PA: DNA double-strand break repair within heterochromatic regions. Biochem Soc Trans 40: 173-178, 2012.

52. Turc-Carel C, Aurias A, Mugneret F, et al: Chromosomes in Ewing's sarcoma. I. An evaluation of 85 cases of remarkable consistency of $\mathrm{t}(11 ; 22)(\mathrm{q} 24 ; \mathrm{q} 12)$. Cancer Genet Cytogenet 32: 229-238, 1988

53. Wang J, Cai Y, Ren C and Ittmann M: Expression of variant TMPRSS2/ERG fusion messenger RNAs is associated with aggressive prostate cancer. Cancer Res 66: 8347-8351, 2006

54. Wang J, Cai Y, Shao LJ, et al: Activation of NF- $\kappa \mathrm{B}$ by TMPRSS2/ERG fusion isoforms through toll-like receptor-4. Cancer Res 71: 1325-1333, 2011.

55. Tomlins SA, Bjartell A, Chinnaiyan AM, Jenster G, Nam RK, Rubin MA and Schalken JA: ETS gene fusions in prostate cancer: from discovery to daily clinical practice. Eur Urol 56 : 275-286, 2009

56. Yuan Y, Zhou L, Miyamoto T, et al: AML1-ETO expression is directly involved in the development of acute myeloid leukemia in the presence of additional mutations. Proc Natl Acad Sci USA 98: 10398-10403, 2001.

57. Licht JD and Sternberg DW: The molecular pathology of acute myeloid leukemia. Hematology Am Soc Hematol Educ Program 2005: 137-142, 2005.

58. Rubnitz JE, Raimondi SC, Halbert AR, et al: Characteristics and outcome of $\mathrm{t}(8 ; 21)$-positive childhood acute myeloid leukemia: a single institution's experience. Leukemia 16: 2072-2077, 2002.

59. Okumura AJ, Peterson LF, Okumura F, Boyapati A and Zhang DE: $\mathrm{t}(8 ; 21)(\mathrm{q} 22 ; \mathrm{q} 22)$ Fusion proteins preferentially bind to duplicated AML1/RUNX1 DNA-binding sequences to differentially regulate gene expression. Blood 112: 1392-1401, 2008.

60. Wang J, Wang M and Liu JM: Domains involved in ETO and human N-CoR interaction and ETO transcription repression. Leuk Res 28: 409-414, 2004.

61. Wang L and Hiebert SW: TEL contacts multiple co-repressors and specifically associates with histone deacetylase-3. Oncogene 20: 3716-3725, 2001

62. Mengeling BJ, Phan TQ, Goodson ML and Privalsky ML: Aberrant corepressor interactions implicated in PML-RARo and PLZF-RAR $\alpha$ leukemogenesis reflect an altered recruitment and release of specific NCoR and SMRT splice variants. J Biol Chem 286: 4236-4247, 2011.

63. Zhang XW, Yan XJ, Zhou ZR, et al: Arsenic trioxide controls the fate of the PML-RAR $\alpha$ oncoprotein by directly binding PML. Science 328: 240-243, 2010.

64. Mueller D, García-Cuéllar MP, Bach C, Buhl S, Maethner E and Slany RK: Misguided transcriptional elongation causes mixed lineage leukemia. PLoS Biol 7: e1000249, 2009.

65. Balgobind BV, Zwaan CM, Pieters R and Van den HeuvelEibrink MM: The heterogeneity of pediatric MLL-rearranged acute myeloid leukemia. Leukemia 25: 1239-1248, 2011.

66. Liu H, Cheng EH and Hsieh JJ: MLL fusions: pathways to leukemia. Cancer Biol Ther 8: 1204-1211, 2009.

67. Krivtsov AV and Armstrong SA: MLL translocations, histone modifications and leukaemia stem-cell development. Nat Rev Cancer 7: 823-833, 2007.
68. Dobson CL, Warren AJ, Pannell R, Forster A and Rabbitts TH: Tumorigenesis in mice with a fusion of the leukaemia oncogene $M l l$ and the bacterial lacZ gene. EMBO J 19: 843-851, 2000.

69. Bernt KM, Zhu N, Sinha AU, et al: $M L L$-rearranged leukemia is dependent on aberrant H3K79 methylation by DOT1L. Cancer Cell 20: 66-78, 2011

70. Daigle SR, Olhava EJ, Therkelsen CA, et al: Selective killing of mixed lineage leukemia cells by a potent small-molecule DOT1L inhibitor. Cancer Cell 20: 53-65, 2011.

71. Liu H, Cheng EH and Hsieh JJ: Bimodal degradation of MLL by $\mathrm{SCF}^{\text {Skp2 }}$ and $\mathrm{APC}^{\mathrm{Cdc20}}$ assures cell cycle execution: a critical regulatory circuit lost in leukemogenic MLL fusions. Genes Dev 21: 2385-2398, 2007.

72. Ayton PM and Cleary ML: Transformation of myeloid progenitors by MLL oncoproteins is dependent on Hoxa7 and Hoxa9. Genes Dev 17: 2298-2307, 2003.

73. Zeisig BB, Schreiner S, García-Cuéllar MP and Slany RK: Transcriptional activation is a key function encoded by MLL fusion partners. Leukemia 17: 359-365, 2003.

74. Okada Y, Feng Q, Lin Y, et al: hDOT1L links histone methylation to leukemogenesis. Cell 121: 167-178, 2005.

75. Wong P, Iwasaki M, Somervaille TC, So CW and Cleary ML: Meisl is an essential and rate-limiting regulator of $M L L$ leukemia stem cell potential. Genes Dev 21: 2762-2774, 2007.

76. So CW, Lin M, Ayton PM, Chen EH and Cleary ML: Dimerization contributes to oncogenic activation of MLL chimeras in acute leukemias. Cancer Cell 4: 99-110, 2003.

77. So CW and Cleary ML: Dimerization: a versatile switch for oncogenesis. Blood 104: 919-922, 2004.

78. Bischof D, Pulford K, Mason DY and Morris SW: Role of the nucleophosmin (NPM) portion of the non-Hodgkin's lymphomaassociated NPM-anaplastic lymphoma kinase fusion protein in oncogenesis. Mol Cell Biol 17: 2312-2325, 1997.

79. Goldman JM and Melo JV: Chronic myeloid leukemia - advances in biology and new approaches to treatment. N Engl J Med 349: 1451-1464, 2003

80. Ladanyi $M$ and Cavalchire G: Molecular variant of the NPM-ALK rearrangement of Ki-1 lymphoma involving a cryptic ALK splice site. Genes Chromosomes Cancer 15: 173-177, 1996.

81. Jhiang SM: The RET proto-oncogene in human cancers. Oncogene 19: 5590-5597, 2000.

82. Zhao X, Ghaffari S, Lodish H, Malashkevich VN and Kim PS: Structure of the Bcr-Abl oncoprotein oligomerization domain. Nat Struct Biol 9: 117-120, 2002.

83. Alberti L, Carniti C, Miranda C, Roccato E and Pierotti MA: RET and NTRK1 proto-oncogenes in human diseases. J Cell Physiol 195: 168-186, 2003.

84. Mizuki M, Ueda S, Matsumura I, Ishiko J, Schwäble J, Serve H and Kanakura Y: Oncogenic receptor tyrosine kinase in leukemia. Cell Mol Biol 49: 907-922, 2003.

85. Mano H: Non-solid oncogenes in solid tumors: EML4-ALK fusion genes in lung cancer. Cancer Sci 99: 2349-2355, 2008.

86. Nagar B, Hantschel O, Seeliger M, Davies JM, Weis WI, Superti-Furga G and Kuriyan J: Organization of the SH3-SH2 unit in active and inactive forms of the c-Abl tyrosine kinase. Mol Cell 21: 787-798, 2006.

87. Chen S, Dumitrescu TP, Smithgall TE and Engen JR: Abl N-terminal cap stabilization of SH3 domain dynamics. Biochemistry 47: 5795-5803, 2008.

88. Mian AA, Oancea C, Zhao Z, Ottmann OG and Ruthardt M: Oligomerization inhibition, combined with allosteric inhibition, abrogates the transformation potential of T315I-positive BCR/ABL. Leukemia 23: 2242-2247, 2009.

89. He Y, Wertheim JA, Xu L, Miller JP, Karnell FG and Choi JK: The coiled-coil domain and Tyr177 of bcr are required to induce a murine chronic myelogenous leukemia-like disease by bcr/abl. Blood 99: 2957-2968, 2002

90. Reddy EP and Aggarwal AK: The ins and outs of bcr-abl inhibition. Genes Cancer 3: 447-454, 2012.

91. Tong Q, Xing S and Jhiang SM: Leucine zipper-mediated dimerization is essential for the $P T C l$ oncogenic activity. $\mathrm{J}$ Biol Chem 272: 9043-9047, 1997.

92. Pillai RN and Ramalingam SS: The biology and clinical features of non-small cell lung cancers with EML4-ALK translocation. Curr Oncol Rep 14: 105-110, 2012.

93. Shaw AT, Yeap BY, Solomon BJ, et al: Effect of crizotinib on overall survival in patients with advanced non-small-cell lung cancer harbouring ALK gene rearrangement: a retrospective analysis. Lancet Oncol 12: 1004-1012, 2011. 
94. Willis TG and Dyer MJ: The role of immunoglobulin translocations in the pathogenesis of B-cell malignancies. Blood 96: 808-822, 2000.

95. Dadi S, Le Noir S, Asnafi V, Beldjord K and Macintyre EA: Normal and pathological V(D)J recombination: contribution to the understanding of human lymphoid malignancies. Adv Exp Med Biol 650: 180-194, 2009.

96. Martinez-Climent JA, Fontan L, Gascoyne RD, Siebert R and Prosper F: Lymphoma stem cells: enough evidence to support their existence? Haematologica 95: 293-302, 2010

97. Graux C, Cools J, Michaux L, Vandenberghe P and Hagemeijer A: Cytogenetics and molecular genetics of T-cell acute lymphoblastic leukemia: from thymocyte to lymphoblast. Leukemia 20 1496-1510, 2006.

98. Van Vlierberghe $\mathrm{P}$, van Grotel M, Beverloo HB, et al: The cryptic chromosomal deletion $\operatorname{del}(11)(\mathrm{p} 12 \mathrm{p} 13)$ as a new activation mechanism of $L M O 2$ in pediatric T-cell acute lymphoblastic leukemia. Blood 108: 3520-3529, 2006.

99. Brake RL, Kees UR and Watt PM: Multiple negative elements contribute to repression of the $H O X 11$ proto-oncogene. Oncogene 17: 1787-1795, 1998.
100. Riz I, Hawley TS, Johnston H and Hawley RG: Role of TLXI in T-cell acute lymphoblastic leukaemia pathogenesis. Br J Haematol 145: 140-143, 2009.

101. Kees UR, Heerema NA, Kumar R, et al: Expression of HOX11 in childhood T-lineage acute lymphoblastic leukaemia can occur in the absence of cytogenetic aberration at 10q24: a study from the Children's Cancer Group (CCG). Leukemia 17: 887-893, 2003.

102. Dadi S, Le Noir S, Payet-Bornet D, et al: TLX homeodomain oncogenes mediate $\mathrm{T}$ cell maturation arrest in T-ALL via interaction with ETS1 and suppression of TCR $\alpha$ gene expression. Cancer Cell 21: 563-576, 2012

103. De Keersmaecker K, Marynen P and Cools J: Genetic insights in the pathogenesis of T-cell acute lymphoblastic leukemia. Haematologica 90: 1116-1127, 2005.

104. Grabher C, von Boehmer H and Look AT: Notch 1 activation in the molecular pathogenesis of T-cell acute lymphoblastic leukaemia. Nat Rev Cancer 6: 347-359, 2006.

105. South AP, Cho RJ and Aster JC: The double-edged sword of Notch signaling in cancer. Semin Cell Dev Biol 23: 458-464, 2012 . 